\title{
Unconventional multiple bonds: coordination compounds of unstable Vth main group ligands
}

\author{
Gottfried Huttner \\ Lehrstuhl für Synthetische Anorganische Chemie, Fakultät für Chemie der \\ Universität Konstanz, P.B. 5560, D-7750 Konstanz
}

\begin{abstract}
Phosphinidene-, arsinidene- and stibinidene-complexes $\mathrm{L}_{\mathrm{n}} \mathrm{M} \cdots \mathrm{X}(\mathrm{R}) \cdots \mathrm{ML}$ ( $\left.\mathrm{X}=\mathrm{P}, \mathrm{As}, \mathrm{Sb}\right)$ contain the main group center $\mathrm{X}$ in a trigonally planar environment. The properties of these species are dominated by strong backbonding from filled metal orbitals at the 16 electron groups $L_{n} M$ into the vacant $p$ orbital of the sextett species $R-\bar{x}$. The synthesis and properties of $L_{n} M \cdots X(R) \cdots M L$ species as well as their chemical interrelation to compounds containing $R-\bar{X}=\underline{X}-R$ or $|X \equiv X|$ ligands will be reported.
\end{abstract}

\section{INTRODUCTION}

Phosphinidenes, $\mathrm{R}-\underline{\underline{\mathrm{P}}}$, arsinidenes, $\mathrm{R}-\overline{\mathrm{As}}$, stibinidenes, $\mathrm{R}-\overline{\overline{\mathrm{Sb}}}$ and bismuthinidenes, $\mathrm{R}-\underline{\overline{\mathrm{Bi}}}$ are the higher homologues of nitrenes, $R-\underline{\underline{N}}$. They contain only a sextett of valence electrons at the main group center and are hence unstable in the free state. While the intermediate

\begin{tabular}{lllll}
$R-\bar{N}$ & $R-\underline{\bar{P}}$ & $R-\overline{\overline{A s}}$ & $R-\overline{\overline{S b}}$ & $R-\overline{\underline{B i}}$ \\
\hline
\end{tabular}

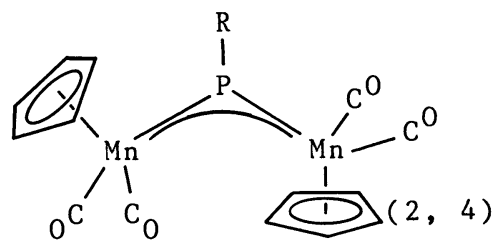

existence of e.g. phosphinidenes, $\mathrm{R}-\underline{\underline{P}}$, had been inferred from trapping and mass spectrometric experiments (1) their ligand capabilities to form binuclear compounds with trigonally planar coordinated main group centers were first demonstrated in 1975 (2). A rich chemistry has since evolved for these types of compounds (3-24) containing partial metal ...X multiple bonds. This will be discussed in the first part (Note a).

Diphosphenes, $R-\bar{P}=\underline{P}-R$, diarsenes, $R-\overline{A s}=\underline{A s}-R$ and distibenes, $R-\overline{S b}=\underline{S b}-R$ have, in accordance with the "double bond rule" been known for quite some time to be unstable (25-26).

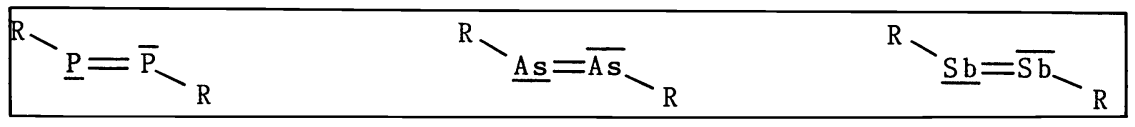

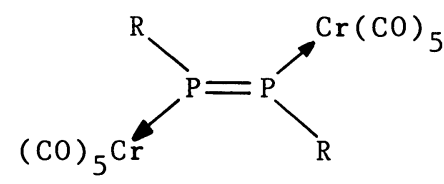

(40)

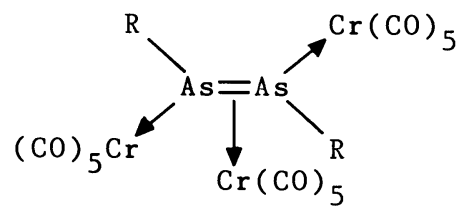

(30)

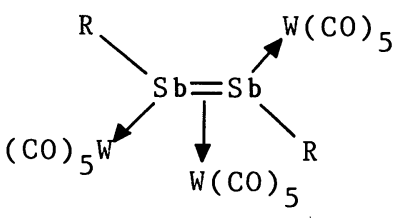

(48)

Only recently has the first $R-\bar{X}=\underline{X}-R$ species been isolated in the free state (27) by using kinetically stabilizing bulky substituents $R$. This finding has attracted many research groups to $R-\bar{X}=\underline{X}-R$ coordination chemistry (28). However, this chemistry has an older origin $(29,30)$ : The coordination chemist, instead of using bulky residues $R$, uses organometallic fragments to protect such unstable entities, and $R-\bar{X}=\underline{X}-R$ derivatives will now be stable even for small groups $R$. The second part of this report will concentrate on the chemistry of this type of compounds.

Note a: The following abbreviations are used throughout:

$\mathrm{X}=\mathrm{P}, \mathrm{As}, \mathrm{Sb}, \mathrm{Bi} ; \mathrm{R}=$ univalent residue e.g. alky1, ary1, ...

$\mathrm{L}_{\mathrm{n}} \mathrm{M}=16$-electron fragment e.g. $(\mathrm{CO})_{5} \mathrm{Cr}, \mathrm{Cp}(\mathrm{CO})_{2} \mathrm{Mn}, \ldots$ 
The dinitrogen homologues $\mathrm{P}_{2}, \mathrm{As}_{2}, \mathrm{Sb}_{2}$ and $\mathrm{Bi}_{2}$ exist only at high temperatures in the dilute gas phase. While showing quite appreciable bond energies (31), they are unstable at normal conditions relative to their elemental modifications which contain three single bonds per atom (e.g. $\mathrm{P}_{4}, \mathrm{As}_{4}$ ) instead of a triple bond, or form metal type lattices.

$$
|\mathrm{P} \equiv \mathrm{P}| \quad|\mathrm{A} \equiv \mathrm{As}| \quad|\mathrm{Sb} \equiv \mathrm{Sb}| \quad|\mathrm{B} i \equiv \mathrm{Bi}|
$$

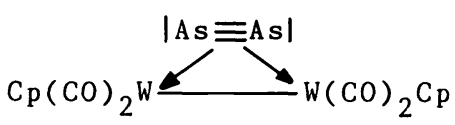

(39)

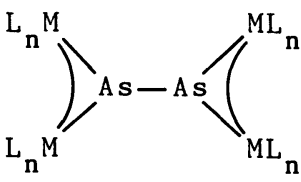

(39)

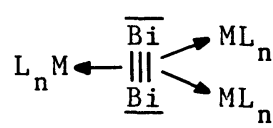

(61)

Again, coordination chemistry can make stable ligands out of these elusive species. The chemistry of $|X \equiv X|$ ligands will be the subject of the final part of this report.

Phosphinidene-, arsinidene-, stibinidene- and bismuthinidene-compounds $L_{n} M \ldots X(R) \ldots-M_{n}$

Synthesis, The prototype $L_{M} M \cdots X(R) \cdots M L$ has been characterized for $X=P$ in 1975 (2). Complexes with $X=A s \quad(9-12)$, Sb $(11,18-20), B i(22)$ became known in the same and the following years. Many different synthetic routes are now available (Scheme 1) and all of

Scheme 1 Synthesis of $\left(L_{n} M\right)_{2} X R$ compounds

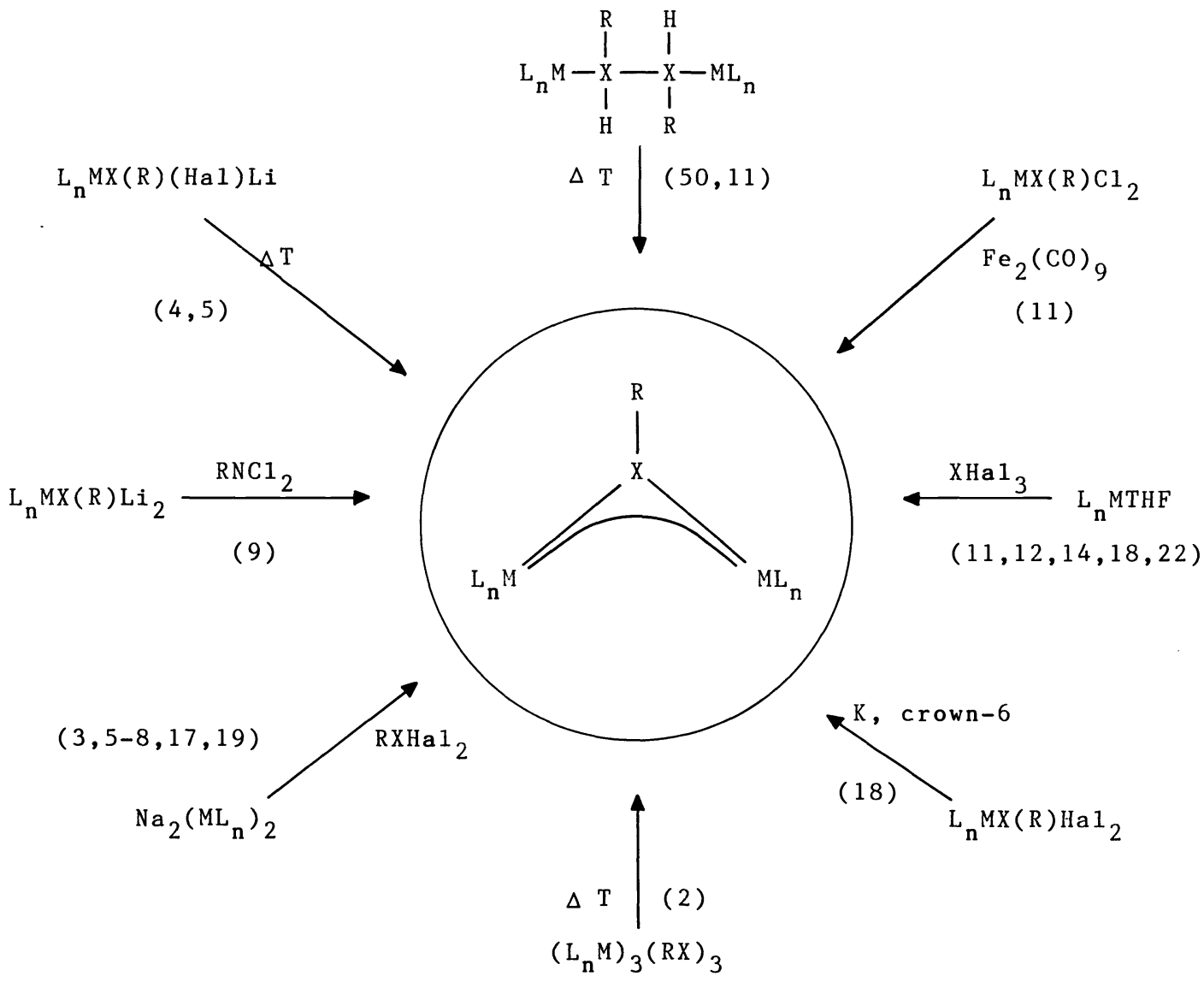

them rely upon the generation of the $R \underline{\bar{X}}$ ligand from a suitable $R \bar{X} R^{\prime}$ precursor in the coordination sphere of a metal. Reactions like the following $(8,32)$ indicate the intermediate existence of mononuclear phosphinidene complexes $(8,32)$, in such reactions (33). 


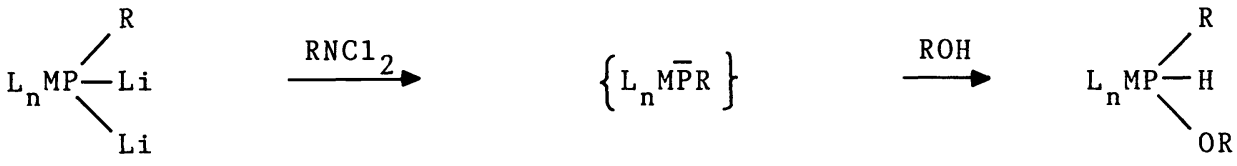

$$
\begin{aligned}
& \mathrm{Na}_{2} \mathrm{Cr}_{2}(\mathrm{CO})_{10} \stackrel{\mathrm{RPHal}_{2}}{\longrightarrow} \quad\left\{(\mathrm{CO})_{5} \mathrm{Cr} \overline{\mathrm{PR}}\right\} \quad \stackrel{\mathrm{C}_{2} \mathrm{H}_{4}}{\longrightarrow} \stackrel{\mathrm{H}_{2}}{\longrightarrow} \stackrel{\mathrm{C}}{\mathrm{CH}_{2}}
\end{aligned}
$$

The apparent high nucleophilicity of these mononuclear species leads finally to the binuclear compounds (34). In recent years the above synthetic approaches (Scheme 1) have also been successfully applied by other groups $(23,24)$.

$$
\mathrm{RPCl}_{2}+\mathrm{Na}_{2} \mathrm{Cr}_{2}(\mathrm{CO})_{10} \longrightarrow(\mathrm{CO})_{5} \overbrace{\mathrm{Cr}(\mathrm{CO})_{5}}
$$

Structure, bonding and spectroscopy. The bonding in ( $\left.L_{M} M\right)_{2} X R$ compounds has been qualitatively interpreted (10) in terms of $\sigma$-donation of the two $k-\bar{X}$ lone pairs to the two 16 electron $L_{n} M$ fragments accompanied by $\pi$-interaction of metal atom lone pairs with the

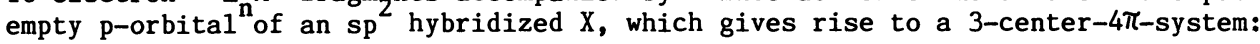<smiles>[R][Y]([Y10])([R])[W]</smiles>

$(2-5,8,9-12,18,19)$

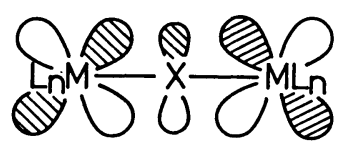

3-Center-4 $\pi$-System

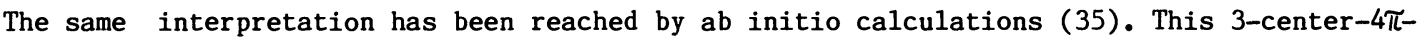
model ( 4 electrons from the two metal atom lone pairs, no electron from the empty $X-p$ valence orbital) is consistent with the properties of $\left(L_{n} M\right)_{2} X R$ compounds: It explains

1. the trigonally planar coordination of $\mathrm{X}$

2. the short $X \cdots M$ bonds

3. the UYY-VIS spectra

4. the ${ }^{3-N M R}$ shifts of $\left(L_{n} M\right)_{2} P R$

5. the reactivity

Scheme 2 Structure spectra and bonding of $\left(L_{n} M\right)_{2} X R$

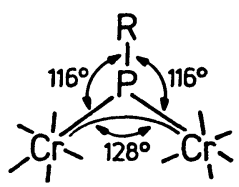

${ }^{d_{C r P}}=230 \mathrm{pm}$

Structure

31p-NMR: $1362 \mathrm{ppm}$

(3)

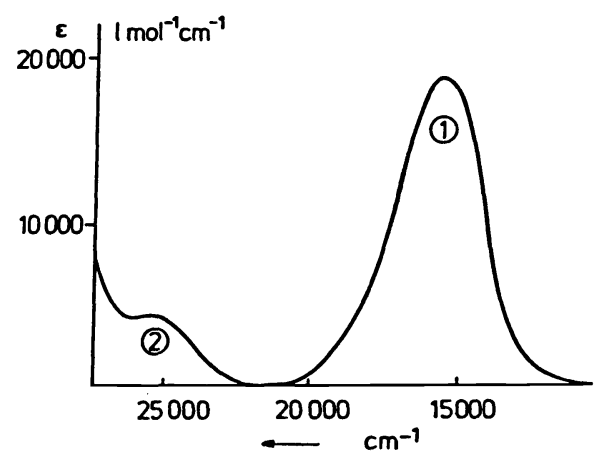

Visible Spectra

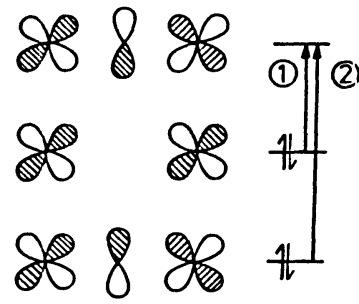

Bonding

$(2-5,7-12,18,19)$

(3) 
Structure, Spectra. The trigonally planar coordination with short $M \cdots X$ bond lengths is common to all $\left(L_{n} M\right)$ XR compounds $(2-5,7-12,18-20,22)$. If $L_{n} M$ has $\pi$-orbitals of different donor quality $\left(\mathrm{e}^{\mathrm{n}} \mathrm{g} \cdot{ }^{2} \mathrm{Cp}(\mathrm{CO}) \mathrm{Mn}\right)$ the better $\pi$-donor orbital will be vertical to the $\mathrm{M}=\mathrm{X}=\mathrm{M}$ plane $(11,19,22,38)$. All compounds $\left(L_{n} M\right)$ XR show bright colours, which is easily understood

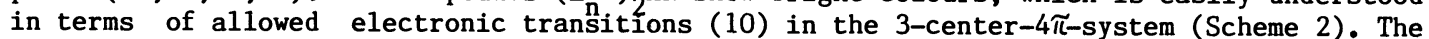
intense long wave length absorptions (Scheme 2) indicate a small HQMO-LUMO separation for such species. This may also be the explanation for the extreme ${ }^{31} \mathrm{P}-\mathrm{NMR}$ low field shifts observed for phosphinidene compounds (Scheme 2). Low lying excited triplet states will significantly contribute to the ground state electronic configuration and hence increase the paramagnetic contribution to the shift $(3-5,7,8)$. The above 3 -center- $4 \pi$-model also explains much of the reactivity of $\left(L_{n} M\right)_{2} X R$.

Reactivity. The crucial type of reaction is the addition of Lewis bases to the $\mathrm{X}$ center of $\left(\mathrm{L}_{n} \mathrm{M}\right)_{2} \mathrm{XR}$ :<smiles>[R][X]([Y10])[W]</smiles>

$(13,15,17,20,36)$

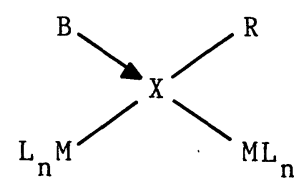

$B \mid=$ Lewis-Base

The electron deficiency of the sextet species $R-\underline{\bar{x}}$ is only partially removed by the interaction with filled metal orbitals in ( $\left.L_{n} M\right)_{2} X R$. Thus, in accord with the above MO-scheme (Scheme 2) Lewis bases add to $X$ to yield tetrahedrally coordinated $X$ in the adducts (3-6, 13-17, 20, 22,36).

In fact the tendency to form adducts is especially strong for the heavier elements and labile intermediate species $\left(L_{n} M\right)_{2} X R$ may be trapped as base adducts $(22,36)$. The on $1 y$ bismuthinidene compound known so far, $\left(\mathrm{Cp}(\mathrm{CO})_{2} \mathrm{Mn}\right)_{2} \mathrm{BiCl}$, is accordingly found to be an

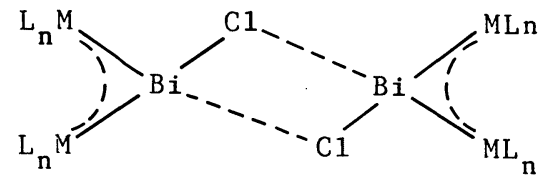

(22)

unsymmetrical dimer in the solid state (22) due to the high electrophilicity of the coordinated BiCl ligand.

Substitution. If in $\left(L_{n} M\right)_{2} X R, R$ is a good anionic leaving group, substitution may occur via an addition elimination sequence $(6,15-17,19-20)$ :

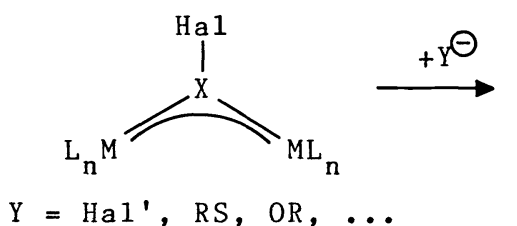

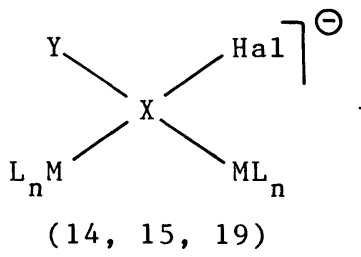

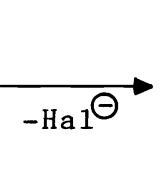

$(14,15,19)$

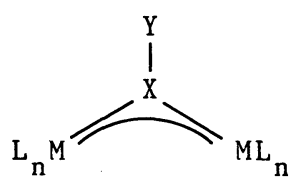

$(15,19)$

Halide substitution in $\left(L_{M} M\right)_{2}$ XHal may also be accomplished by electrophilic agents $\left(\mathrm{BR}_{3}, \mathrm{AlR}_{3}\right)(15,17)$. These reactions follow a different mechanism $(15,17)$ and are especially useful for exchanging Hal versus alkyl or aryl groups.

Substitution by organometallic nucleophiles leads to compounds containing "naked" trigonally planar coordinated $X$ atoms (see below) $(37,38)$.

Chelation. Chelation with monovalent chelate ligands implies addition and substitution at the same time. Since both pathways are available for $\left(L_{n} M\right)_{2} X H a 1$, the formation of chelates may be anticipated. It is in fact a general reaction $(6,16,17)$.

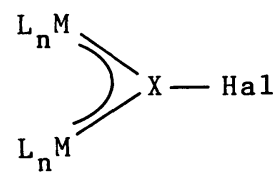

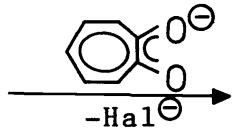<smiles>[Y11][X]1([Y11])Oc2ccccc2O1</smiles>

Many examples of this reaction behaviour with different chelating ligands and for $X=P(6)$ as well as As $(16,17)$ have been documented. The $\left(L_{n} M\right)_{2}$ bound ligands are interesting in 
themselves, since they contain $X$ in the formal +1 oxidation state and are, like the mere base adducts $B \rightarrow X-R(13-15,16,20,36)$ not known in the free state.

$$
\mathrm{R}_{3} \mathrm{P} \rightarrow \underline{\bar{x}}_{\mathrm{R}}
$$

Reductive coupling. Reduction of $\left(L_{M} M\right)_{2}$ XHal may occur by simple reductive coupling like in the treatment of $\left(\mathrm{C} p(\mathrm{CO})_{2} \mathrm{Mn}\right)_{2} \mathrm{AsCl}$ with $\mathrm{Zn}$, leading to a novel form of coordinated diarsenic (39):

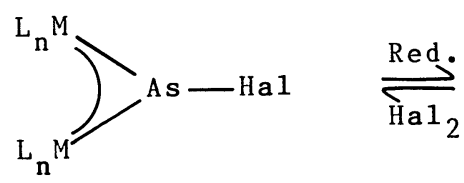

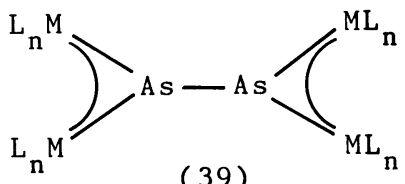

Halogenation of the $\mathrm{As}_{2}$-product leads back to the starting material (39).

With organometallic nucleophiles reduction may be induced in a stepwise manner like in the reaction of $\left(\mathrm{Cr}(\mathrm{CO})_{5}\right)_{2} \mathrm{AsCl}$ with $\mathrm{CpM}(\mathrm{CO})_{3} \mathrm{Na}(\mathrm{M}=\mathrm{Mo}, \mathrm{W})(39)$.

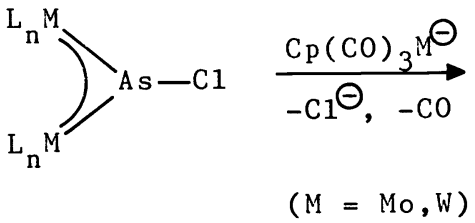

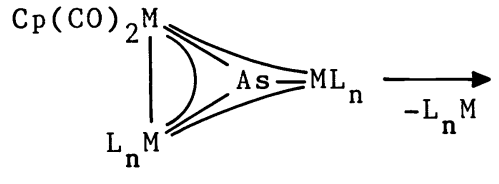

$(37-39)$

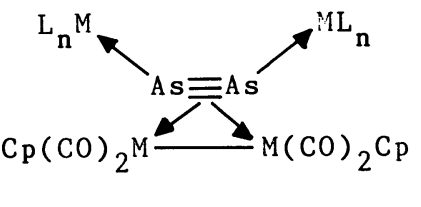

(39)

In the first step this leads to a compound containing triply bridging trigonally planar coordinated arsenic, which then, by splitting off one $L_{n} M$ with $R_{3} P$, dimerizes to give a side on as well as end on coordinated diarsenic entity (39).

Dimerisation of $R \overline{\underline{X}}$.
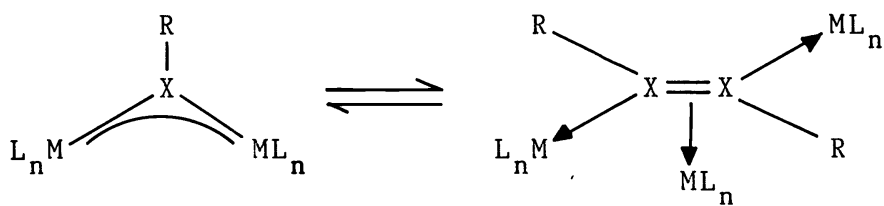

There are several reactions which indicate that the above transformation of $R-\overline{\bar{X}}-$ compounds into $R-\bar{X}=\underline{X}-R$ derivatives is a possible reaction pathway. The forward reaction is observed for $\left((\mathrm{CO})_{5} \mathrm{Cr}\right)_{2} \mathrm{PR}(8,40)$ while the backward transformation has been documented for a<smiles>[R][Sb]([Y10])([Y10])[R]</smiles>

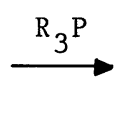

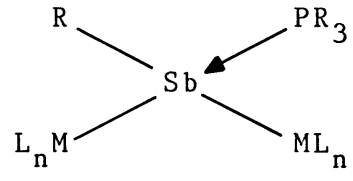

(20)

distibene compound. The $\mathrm{Sb}=\mathrm{Sb}$-bond is split by the interaction with Lewis bases to yield the base adducts of the corresponding stibinidene compound (20).

Valence tautomeric forms. For a compound $\left(L_{n} M\right){ }_{2} X R$ ( $L_{n} M=16$ electron fragment) there are

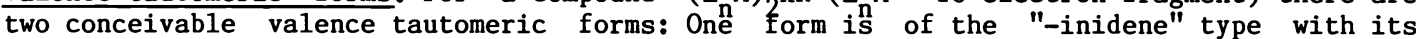
delocalized 3-center-4 $\pi$-System. In the other form these four electrons are localized:

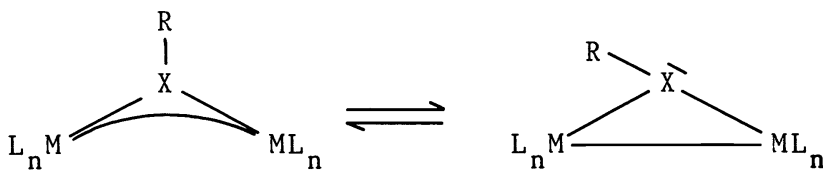

Two of them form an M-M bond and the other two are localized as a lone pair at the center $X$. In this second form $X$ is a Lewis base center while in the "-inidene" type form $X$ behaves as a Lewis acid. For $\left((\mathrm{CO})_{5} \mathrm{~W}\right)_{2} \mathrm{SbR}$ derivatives of both forms may be obtained from the same reaction mixture depending on wether a Lewis base $\left(R_{3} P\right)$ or a Lewis acid $\left(W(C O)_{5}\right)$ are 
added (20). The Lewis basic $M-M$ bonded forms, $L_{n} M-M L_{n}-X R$ are in fact metallacyclic phosphanes, arsanes or stibanes. Their chemistry has been extensively explored in connection with cluster reactivity (46).

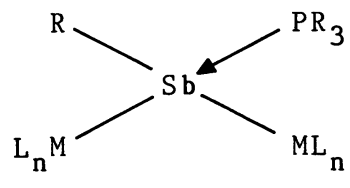

$(20,36)$

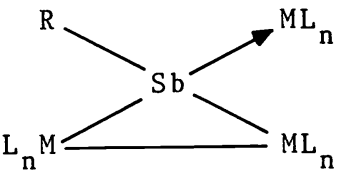

(20)

The equilibrium between the two valence tautomeric forms is delicately controlled by steric and electronic factors: $\mathrm{Cp}(\mathrm{CO})_{2} \mathrm{Mn}$ and $\mathrm{M}(\mathrm{CO})_{5}(\mathrm{M}=\mathrm{Cr}, \mathrm{Mo}, \mathrm{W})$ as $\mathrm{L} M$ fragments appear to favour the open "-inidene" form. $\mathrm{Fe}(\mathrm{CO})_{4}$, on the other hand, generally gives derivatives of the closed form. $R-\overline{\mathrm{Te}}^{+}$, which is isoeletronic with $\mathrm{R}-\overline{\mathrm{Sb}}$, is coordinated in the $M-M$ bonded form even with $\mathrm{Cp}(\mathrm{CO})_{2} \mathrm{Mn}(42)$ as is $\mathrm{Cl}-\overline{\mathrm{Sb}}$ in $\left(\mathrm{Cp}(\mathrm{CO})_{2} \overline{\mathrm{Mn}}\right)_{3} \mathrm{SbCl}$ (12) while $\mathrm{C} 1-\underline{\underline{\mathrm{As}}}$ gives the "-inidene" type dinuclear compound $(11,12, \overline{17})$.

Planar coordination of $\mu_{3}-X$ ligands. Compounds containing triply bridging $X$ atoms in a planar coordination may be described as organometallic substitution products of "-inidene" complexes. In fact many of these species $(37,38,43)$ including the first examples of this type of coordination (37) have been synthesized from "-inidene" compounds as the starting materials. One example has already been given above and Scheme 3 illustrates a selection of structurally fully characterized compounds.

Scheme 3 Planar coordination of $\mu_{3}-\mathrm{X}$; Structurally characterized examples $(37,38,43,63)$.<smiles>CC(C)(C)C1[C@H](C(C)(C)C)C(C(=O)O)[C@H]1C(C)(C)C</smiles>

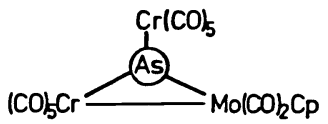<smiles>CC(C)(C)[14C](=O)[N+]([O-])([O-])[O-]</smiles>

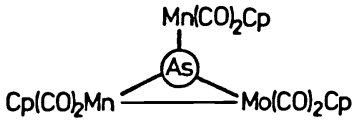

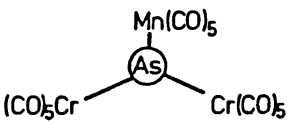

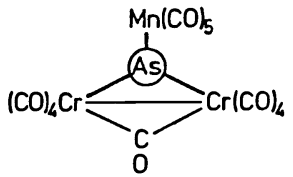

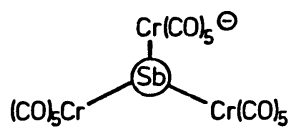<smiles></smiles>

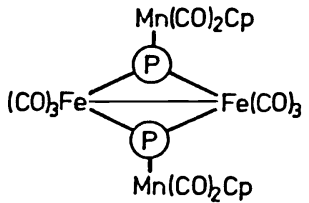<smiles></smiles>

Two reactions may serve to illustrate the synthetic principles: $\left((\mathrm{CO})_{5} \mathrm{~W}\right)_{2} \mathrm{SbCl}$ reacts with $\mathrm{Na}_{2} \mathrm{~W}_{2}(\mathrm{CO})_{10}$ to give the symmetric anion $\mathrm{Sb}\left(\mathrm{W}(\mathrm{CO})_{5}\right)_{3}(38)$.

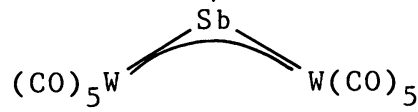

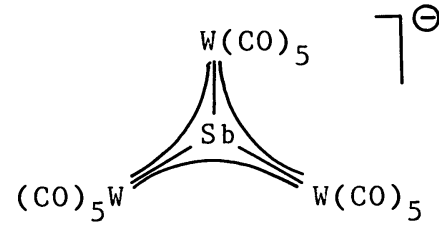

(38)

Treatment of $\left((\mathrm{CO})_{5} \mathrm{Cr}\right)_{2} \mathrm{AsCl}$ with $\mathrm{Mn}(\mathrm{CO})_{5}{ }^{-}$yields the substitution product first, which then decarbonylates to the more condensed species, which again contains a planar $\mu_{3}$-arsenic atom. 


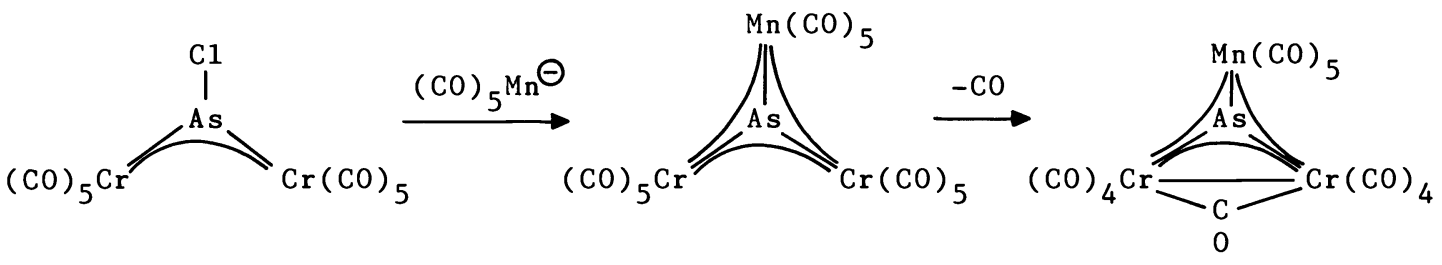

(38)

This type of trigonal planar $\mu_{3}$-coordination of a main group center may be found for sixth (44) and fourth (45) group elements as well (Scheme $3,(38,63)$ ).

Phosphinidene complexes as ligands. The 3 -center-4 $\pi$-system of $"$-inidene" compounds is isolobal to the $\pi$-system of an allylic anion (10). In fact, $\eta^{3}$-allylic type side on coordination of $\left(\mathrm{L}_{n} \mathrm{M}\right) 2_{2} \mathrm{XR}$ is quite common (46)

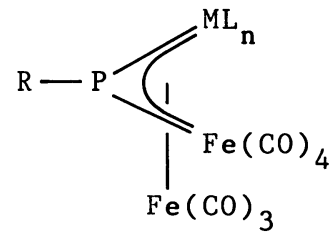

$(41,46 a)$

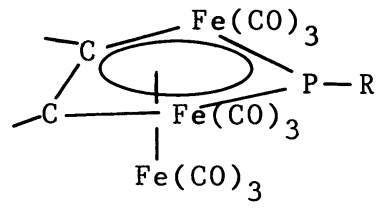

$(46 b)$

and has been interpreted (46) in terms of this isolobal analogy. The characteristic trigonally planar $X$ coordination may also be observed for metallacyclic $\pi-1$ igands of clusters (46); it has a similar rationale (46).

$R-X=\bar{X}-R$ derivatives $(X=P, A s, S b)$.

Side-on coordinated organometallic derivatives of the generally unstable $R-\bar{X}=\underline{X}-R$ ligands were first reported in 1971 (47).

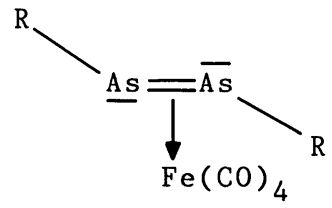

(47)<smiles>[R][Y]([Y10])=[Y]([R])[R]</smiles>

$(30,40,48)$

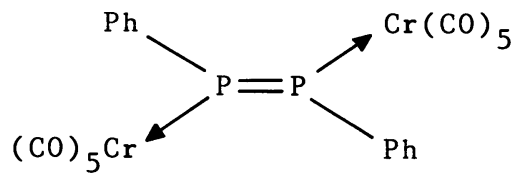

(40)

The capability of the $X$ lone pairs to coordinate up to two additional $L$ M fragments was first observed in 1976 (30). The electronic as well as steric protection of the $\mathrm{X}=\mathrm{X}$ double bond in such species allows for the synthesis of $R-\bar{X}=X-R$ ligand entities even with small groups $R$, where the free species $R-\bar{X}=\underline{X}-R$ itself would not be stable. Especially noticeable in this respect are the $L_{M} M$ derivatives of the highly unstable $R-\overline{S b}=\underline{S b}-R$ (48). Side on coordination is not a prerequisite for stabilisation, since for example unstable $\mathrm{Ph}-\overline{\mathrm{P}}=\underline{\mathrm{P}}-\mathrm{Ph}$ may be stabilized by mere end-on $L_{M} M$ bonding (40). If the substituents $R$ are bulky groups, the species $R-\bar{X}=\underline{X}-R$ may in some cases be isolated in the free state $(27,28)$. Upon complexation these stable ligands give the expected coordination compounds (28).

Synthesis. In those cases where the free $R-\bar{X}=\underline{X}-R$ species is unstable the general synthetic approach consists in reductive coupling of $\mathrm{RXHal}_{2}$ in the presence of a suitable organometallic entity.

An especially effective strategy consists in dehalogenation and complexation by $\mathrm{Na}_{2} \mathrm{M}_{2}(\mathrm{CO}){ }_{10}$ $(M=\mathrm{Cr}, \mathrm{Mo}, \mathrm{W})(30,40,48)$ starting from $\mathrm{RXHal}_{2}(\mathrm{X}=\mathrm{P}, \mathrm{As}, \mathrm{Sb})$

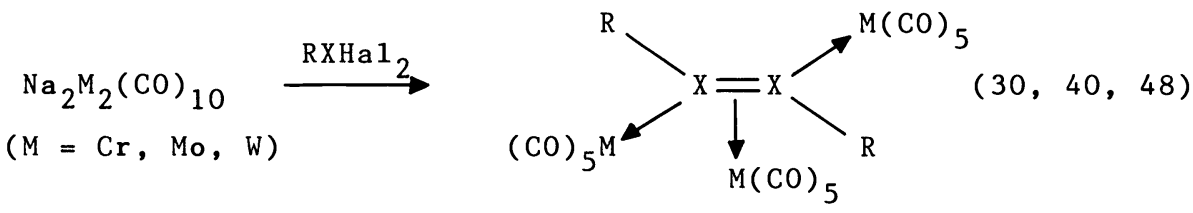

A reaction sequence of inverted polarity $\left(\mathrm{L}_{n} \mathrm{MAs}(\mathrm{R}) \mathrm{H}_{2} \longrightarrow \mathrm{L}_{n} \mathrm{MAs}(\mathrm{R}) \mathrm{Li}_{2} \rightarrow\left(\mathrm{L}_{n} \mathrm{M}\right){ }_{3} \mathrm{RAs}=\underline{\mathrm{As}} \mathrm{R}\right)$ has been used to construct $R-\overline{A s}=A s-R$ derivatives (30). An especially simple approach is the dehydrogenation of diarsane compounds $\left(\mathrm{L}_{\mathrm{n}} \mathrm{MAs}(\mathrm{R}) \mathrm{H}\right)_{2}(49)$ by $\mathrm{Pd}$ or $\mathrm{Pt}(50)$. In the presence of auxiliary ligands L, Pd-dehydrogenation results in the formation of Pd complexes (50). 


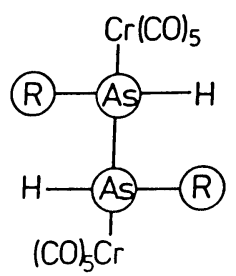

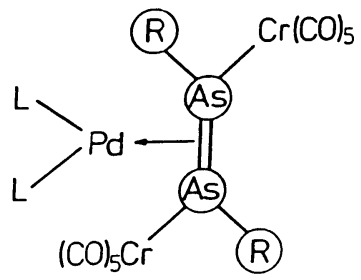

Platinum can not be incorporated into the product in this way and dehydrogenation is catalytic as it is with Pd if no $\mathrm{L}$ is added. The dehydrogenation products may be trapped by

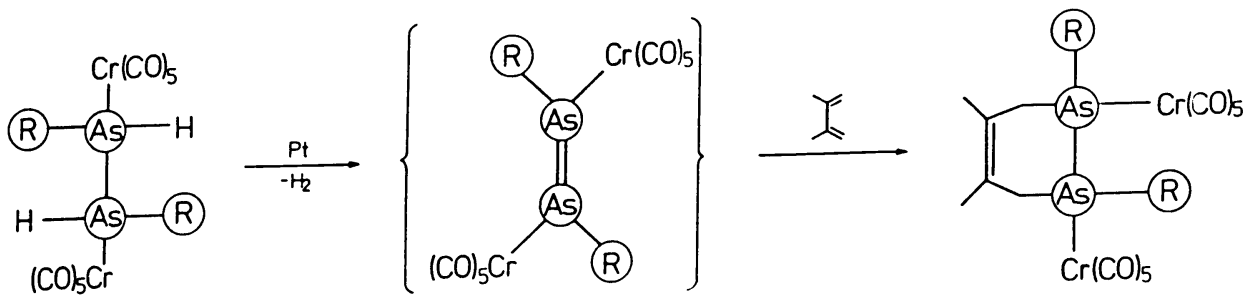

their Diels-Alder en type activity (50). The chemical interrelation between $\left(L_{n} M\right) 2^{X R}$ and $\left(L_{n} M\right)_{n}(R-\bar{X}=\underline{X}-R)$ has already been pointed out above $(50)$.

Structure, bonding and spectroscopy. $R-\bar{X}=\underline{X}-R$ derivatives with only terminal $L M$ complexation have a planar framework with $X=X$ bonds as short (40) as those in the few known

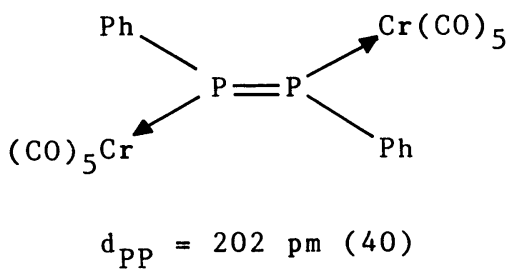

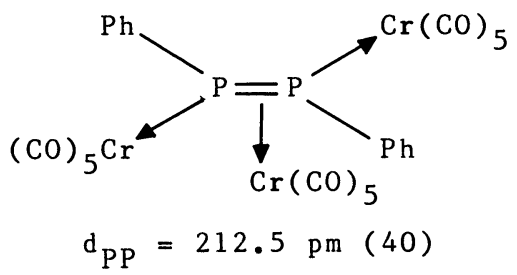

uncomplexed $R-\bar{X}=\underline{X}-R$ species (40). Additional side-on coordination lengthens the $X=X$ bond as expected.

The $R-\bar{X}=\underline{X}-R$ group normally displays E-stereochemistry; only with $R=$ mesityl is the

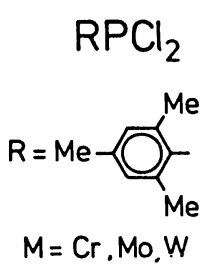

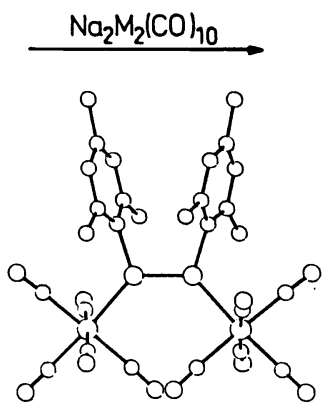

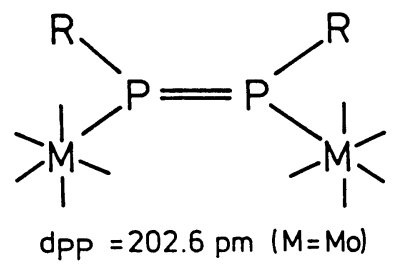

Z-arrangement thermodynamically favoured $(5,7)$; E-Z isomerization is possible in some cases (51).

The end-on coordinated $L_{n} M$ groups build up an extended $\pi$-system in coupling with the $\pi$ system of the $R-\bar{X}=\underline{X}-R$ part. $R-\bar{X}=\underline{X}-R, L, M R-\bar{X}=\underline{X}-R$ and $L, M R-\bar{X}=\underline{X}-R M L$ may thus be described as

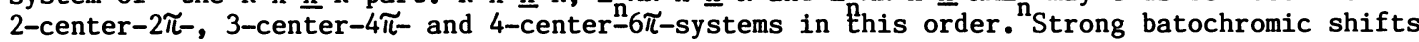
are hence expected in this series for the electronic transitions and are in fact observed $(7,52)$. Side-on coordination disturbs this $\pi$-system and results in a different absorption pattern with the appropriate shift (40). 
$R-\bar{P}=P-R$ groups have been found to serve as cluster constituents $(8,53)$. A chromium compound of this type (8) is especially noticeable, since only very few chromiumcarbonyl clusters (54) are known and only one of them has been structurally fully characterized (54a).

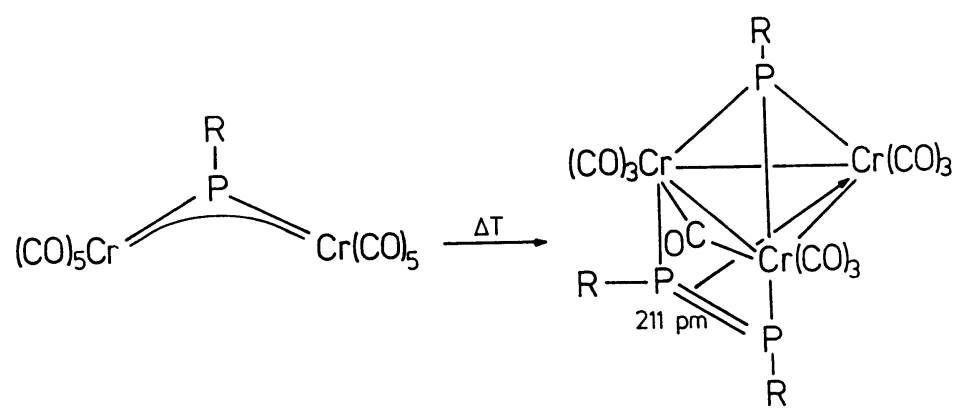

Reactions. The transformation of $R \bar{X}=\underline{X} R\left(M L_{n}\right)_{3}$ into derivatives of $\left(L_{n} M\right)_{2} X R$ has already been mentioned (20).

The reactions characteristic of complexes containing non coordinated $\mathrm{X}=\mathrm{X}$ bonds are additions to the double bond which show a high degree of stereoselectivity $(50,55)($ Scheme 4).

Scheme 4 Reactions of the $\mathrm{P}=\mathrm{P}$ double bond $(50,55)$.

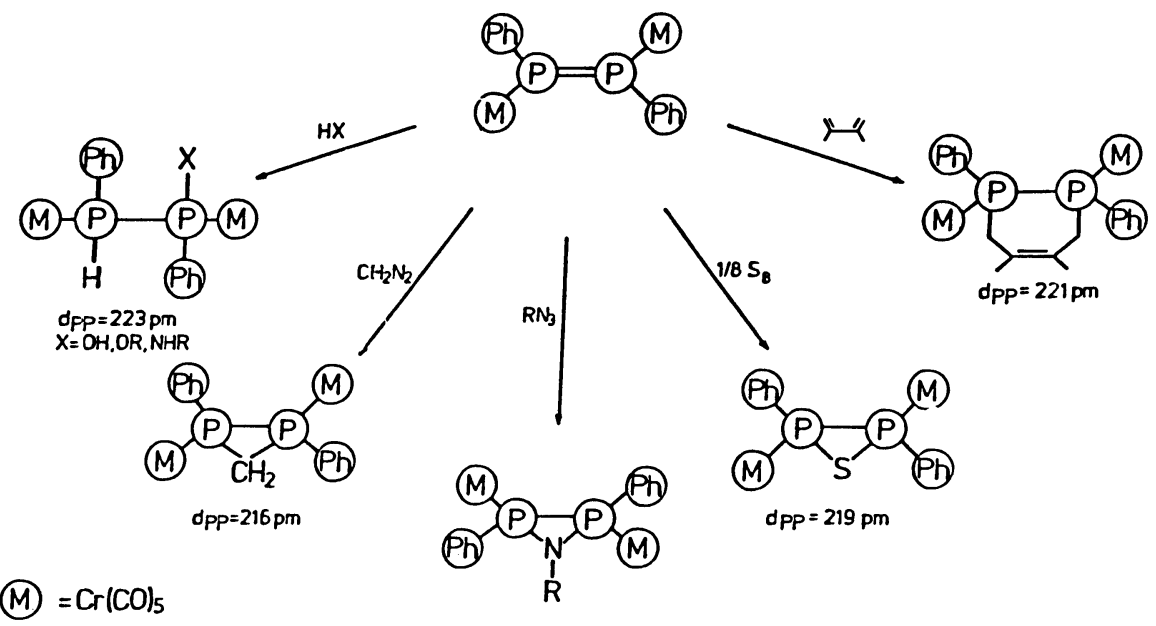

The preparative utilization of this stereoselectivty towards for example the possible synthesis of chiral diphosphanes has yet to be explored.

\section{$X_{2}$ derivatives $(X=P, A s, S b, B i)$}

Alkine type bonding. Compounds with side on coordinated $X_{2}$ units in which $X_{2}$ is coordinated in quite the same way as an alkine would be, have been known since 1969 ( 56 ). In this case the $\mathrm{X}_{2}$ groups are side on coordinated as four electron donors (56); they may bind up to two 16 electron $L_{n} M$ fragments $(39,58)$ via their $|X \equiv X|$ lone pairs.

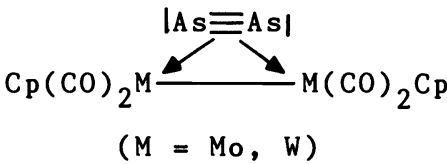

(39)

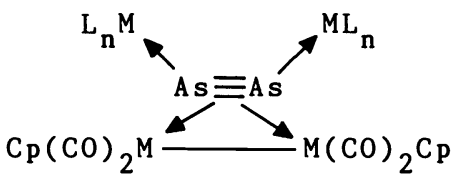

(39)

The bond length data for such compounds are consistent with the assumption of an $|X \equiv X|$ triple bond which is lengthened by the side on coordination $(39,56,58)$. The synthesis of such compounds may be accomplished by the reductive coupling of $\mathrm{XHal}_{3}$ educts in the periphery of suitable organometallic reagents; "-inidene" type compounds have been shown to be the intermediates in some cases (see above $(20,36,39)$ ). Other approaches, starting from $P_{4}(59)$ or $\mathrm{AsH}_{3}$ (24) have been developed. In addition, a transformation from side-on triply coordinated $\mathrm{X}_{2}$ (39) into the above side-on doubly coordinated form has been observed. 
Diarsinidene type bonding. Reductive coupling of $\left(\mathrm{L}_{n} \mathrm{M}\right)_{2}$ AsHal has demonstrated for the first time another form of $\mathrm{X}_{2}$ coordination (39).

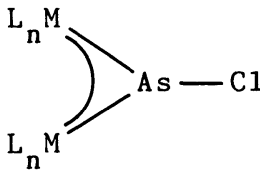

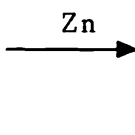

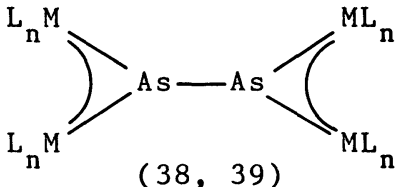

In this form $A s_{2}$ is coordinated out of its diarsinidene valence state $(\overline{\mathrm{As}}-\overline{\mathrm{As}}$ ) and the two arsenic atoms show the trigonal planar coordination typical of arsinidene complexes (9-12). The derivative with $\mathrm{L}_{n} \mathrm{M}=\mathrm{Cp}(\mathrm{CO})_{2} \mathrm{Mn}$ has also been obtained from the reaction of $\mathrm{L}_{\mathrm{n}}$ MTHF with $\mathrm{AsH}_{3}$ (29).

Threefold side-on coordination. Compounds containing $\mathrm{X}_{2}$ ligands as side-on coordinated six electron donor entities have been obtained from $\mathrm{XHal}_{3}$ by reductive coupling $(39,48,60,61)$.

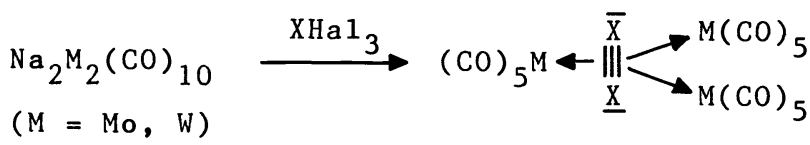

$$
\begin{aligned}
& (39,48,60,61)
\end{aligned}
$$

In these star type complexes the $\mathrm{X}_{2}$ entities are side on coordinated to three 16 electron fragments and would thus be expected to donate a total of six electrons to the three side on coordinated $L_{n} M$-fragments. Since $X_{2}$ molecules are $4 \pi$-systems like alkines, by their $\pi$ system alone they can only act as four electron donors (see above). The rationale to the observed side on coordination by $3 \mathrm{~L}_{\mathrm{n}} \mathrm{M}$ fragments, where the $\mathrm{X}_{2}$ entity has to donate six electrons, consists in the EHT based asumption (61) that in addition to the $4 \pi$-electrons the bonding $\sigma$-pair can also act as a donor.

Scheme 5 Structure and Bonding in $\mathrm{X}_{2}\left(\mathrm{M}(\mathrm{CO})_{5}\right)_{3}$.
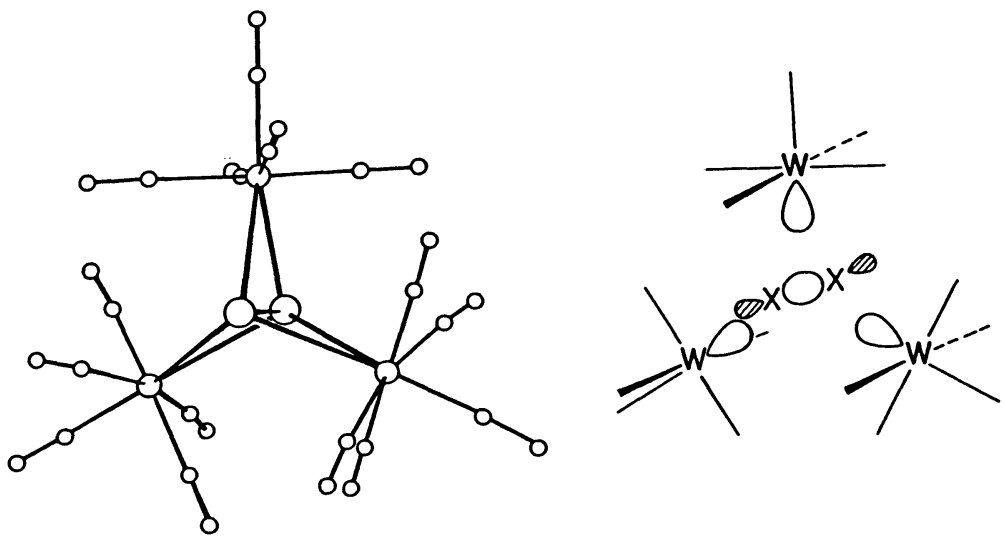

In MO terms this type of coordination is then possible because there is a) efficient overlap between the $L_{M} M-\sigma$-acceptor orbitals and the bonding $X_{2}-\sigma$-orbital and b) a good correspondence in energy between the relevant donor and acceptor orbitals (61). The short $\mid \mathrm{X} \equiv \mathrm{XI}$ distances $\left((\mathrm{CO})_{5} \mathrm{~W}\right)_{3} \mathrm{X}_{2}$ : $\mathrm{X}=\mathrm{As} 227.9 \mathrm{pm}(61), \mathrm{X}=\mathrm{Sb} 266.3 \mathrm{pm}(49), \mathrm{X}=\mathrm{Bi} 281.8 \mathrm{pm}$ (62)) are consistent with this model.

\section{Acknowledgement}

The laborious efforts of diligent and enthusiastic coworkers (names given in references) are gratefully acknowledged. Thanks are due to the Deutsche Forschungsgemeinschaft and the Fond der Chemischen Industrie for financial support.

\section{REFERENCES}

1. U.Schmidt, Angew. Chem. 87, 535 (1975); Angew. Chem. Int. Ed. Eng1. 14, 523 (1975).

2. G.Huttner, H.-D.Müller, A.Frank and H.Lorenz, Angew. Chem. 87, 714 (1975); Angew. Chem. Int. Ed. Engl. 14, 705 (1975).

3. G.Huttner, J.Borm and L.Zsolnai, J. Organomet. Chem. 263, C33 (1984).

4. H.Lang, G.Mohr, 0.Scheidsteger and G.Huttner, Chem. Ber. 118, 574 (1985).

5. H.Lang, Dissertation Universität Konstanz, 1985 
6. H.Lang, L.Zsolnai and G.Huttner, Z. Naturforsch. 40b, 500 (1985).

7. H.Lang, 0.Orama and G.Huttner, J. Organomet. Chem. in press.

8. J.Borm and G.Huttner unpublished results; J.Borm, Dissertation Universität Konstanz, 1985.

9. G.Huttner and H.-G.Schmid, Angew. Chem. 87, 454 (1975); Angew. Chem. Int. Ed. Eng1. 14,433 (1975).

10. G.Huttner, J.v.Seyer1, M.Marsili and H.-G.Schmid, Angew. Chem. 87, 455 (1975); Angew. Chem. Int. Ed. Eng1. 14, 434 (1975).

11. J.v.Seyer1, U.Moering, A.Wagner, A.Frank and G.Huttner, Angew. Chem. 90, 912 (1978); Angew. Chem. Int. Ed. Eng1. 17, 844 (1978).

12. J.v.Seyer1, L.Wohlfahrt and G.Huttner, Chem. Ber. 113, 2868 (1980).

13. J.v.Seyer1 and G.Huttner, Angew. Chem. 91, 244 (1979); Angew. Chem. Int. Ed. Eng1. 18, 233 (1979).

14. J.v.Seyer1, B.Sigwarth and G.Huttner, Chem. Ber. 114, 727 (1981).

15. J.v.Seyer1, B.Sigwarth, H.-G.Schmid, G.Mohr, A.Frank, M.Marsili and G.Huttner, Chem. Ber. 114, 1392 (1981).

16. J.v.Seyer1, B.Sigwarth and G.Huttner, Chem. Ber. 114, 1407 (1981).

17. B.Sigwarth, L.Zsolnai, O.Scheidsteger and G.Huttner, J. Organomet. Chem. 235, 43 (1982).

18. J.v.Seyer1 and G.Huttner, Angew. Chem. 90, 912 (1978); Angew. Chem. Int. Ed. Eng1. 17, 834 (1978).

19. U.Weber, L.Zsolnai and G.Huttner, J. Organomet. Chem. 260, 281 (1984).

20. U.Weber, G.Huttner, O.Scheidsteger and L.Zsolnai, J. Organomet. Chem. 289, 357 (1985).

21. U.Weber, L.Zsolnai and G.Huttner, Z. Naturforsch. in press.

22. J.v.Seyer1 and G.Huttner, J. Organomet. Chem. 193, 207 (1980).

23. K.M.F1ynn, B.D.Murray, M.M.01mstead and P.P.Power, J. Am. Chem. Soc. 105, 7460 (1983); R.A.Jones and B.R.Whittlesey, Organometallics 3 , 469 (1984).

24. W.A.Herrmann, B.Koumbouris, T.Zahn and M.L.Ziegler, Angew. Chem. 96, 802 (1984), Angew. Chem. Int. Ed. Eng1. 23, 812 (1984).

25. F.Kober, Chemiker Zeitung 105, 199 (1981).

26. For the history of this problem see: A.S.Levison, J. Chem. Ed. 54, 99 (1977); H.C.Nelson, ibid. 718 (1977); A.S.Levison, ibid. 718 (1977).

27. M.Yoshifuji, I.Shima and N.Inamoto, J. Am. Chem. Soc. 103, 4587 (1981); ibid. 104,6167 (1982).

28. For a recent review see: A.H.Cowley, Polyhedron 3 , 389 (1984).

29. B.0. West, Homoatomic Rings, Chains and Macromolecules of the Maingroup Elements, Chapter 18, Page 409, Editor A.L.Rheingold.

30. G.Huttner, H.-G.Schmid, A.Frank and 0.Orama, Angew. Chem. 88, 255 (1976); Angew. Chem. Int. Ed. Eng1. 15, 234 (1976).

31. A.G.Gaydon, Dissociation Energies and Spectra of diatomic Molecules, $3^{\text {rd }}$ edition, Chapman Hall, London 1968.

32. G.Huttner and H.-D.Mü1ler, Angew. Chem. 87, 596 (1975); Angew. Chem. Int. Ed. Eng1. 14, 471 (1975).

33. Similar trapping experiments have also been done by: F.Mathey, Phos, and Sulfur 18, 101 (1983); A.Marinetti and F.Mathey, Organometallics 3 , 456 (1984).

34. For an explanation in terms of 4 electron repulsions see: A.Winter, G.Huttner. L.Zsolnai, P.Kroneck and M.Gottlieb, Angew. Chem. 96, 986 (1984); Angew. Chem. Int. Ed. Eng1. 23, 975 (1984).

35. N.M.Kostic and R.F.Fenske, J. Organomet. Chem. 233, 337 (1982).

36. B.Sigwarth, U.Weber, L.Zsolnai and G.Huttner, Chem. Ber, in press.

37. G.Huttner, B.Sigwarth, J.v.Seyer1 and L.Zsolnai, Chem. Ber. 115, 2035 (1982).

38. G.Huttner, U.Weber, B.Sigwarth, 0.Scheidsteger, H.Lang and L.Zsolnai, J. Organomet. Chem. 282, 331 (1985).

39. G.Huttner, B.Sigwarth, 0.Scheidsteger, L.Zsolnai and 0.Orama, Organometallics 4 , 326 (1985).

40. J.Borm, L.Zsolnai and G.Huttner, Angew. Chem. 95, 1018 (1983); Angew. Chem. Int. Ed. Eng1. 22, 977 (1983); Angew. Chem. Supp1. 1983, 1477.

41. G.Huttner, G.Mohr, P.Friedrich and H.-G.Schmid, J. Organomet. Chem. 160, 59 (1978); G.Huttner, G.Mohr and P.Friedrich, Z. Naturforsch. 33b, 1254 (1978); G.Huttner, J.Schneider, H.D.Muiller, G.Mohr, J.v.Seyer1 and L.Wohlfahrt, Angew. Chem. 91,82 (1979); Angew. Chem. Int. Ed. Eng1. 18, 77 (1979); R.L.De, J.v.Seyer1 and G.Huttner, J. Organomet. Chem. 178, 319 (1979); J.Schneider, L.Zsolnai and G.Huttner, Chem. Ber. 115, 989 (1982); H.Schäfer-Stah1, J.Schneider and G.Huttner, Z. Naturforsch. 37b, $\frac{110}{610}$ (1982); J.Schneider, L.Zsolnai and G.Huttner, Cryst. Struct. Commun. 11, 1233 (1982); J.Schneider, M.Minelli and G.Huttner, J. Organomet. Chem. in press; K.Knoll, G.Huttner, L.Zsolnai, I.Jibril and M.Wasiucionek, J. Organomet. Chem, in press.

42. G.Huttner, S.Schuler, M.Gottlieb, M.Minelli and L.Zsolnai, to be published.

43. H.Lang, L.Zsolnai and G.Huttner, Angew. Chem. 95, 1016 (1983); Angew. Chem. Int. Ed. Eng1. 22, 976 (1983); Angew. Chem. Suppl. 1983, 1451.

44. M.Herberhold, D.Reiner and D.Neugebauer, Angew. Chem. 95, 46 (1983); Angew. Chem. Int. Ed. Eng1. 22, 59 (1983); Angew. Chem. Supp1. 1983, 10. 
45. W.Gäde and E.Weiss, J. Organomet. Chem. 213, 451 (1981); W.A.Herrrmann, J.Weichmann, U.Kusthardt, A.Schäfer, R.Hörlein, C.Hecht, C.Voss and R.Serrano, Angew.Chem. 95, 1019 (1983); Angew. Chem. Int. Ed. Eng1. 22, 979 (1983); Angew. Chem. Suppl. 1983, 1543.

46. a) G.Huttner, G.Mohr and A.Frank, Angew. Chem. 88, 719 (1976); Angew. Chem. Int. Ed. Eng1. 15, 687 (1976);

b) K.Knol1, 0.Orama and G.Huttner, Angew. Chem. 96, 989 (1984); Angew. Chem. Int. Ed. Eng1. 23, 976 (1984).

47. P.S.Elmes, P.Leverett and B.0.West, J. Chem. Soc. Chem. Commun. 1971, 747; J.C.Green, M.L.H.Green and G.E.Morris, J. Chem. Soc. Chem. Commun. 1974, 212; E.Cannillo, A.Coda, K.Prout and J.-C.Daran, Acta Cryst. B33, 2608 (1977).

48. G.Huttner, U.Weber, B.Sigwarth and O.Scheidsteger, Angew. Chem. 94,210 (1982); Angew. Chem. Int. Ed. Eng1. 21, 215 (1982); Angew. Chem. Supp1. 1982, 411 .

49. G.Huttner, H.-G.Schmid and H.Lorenz, Chem. Ber. 109,3741 (1976).

50. G.Huttner and I.Jibril, Angew. Chem. 96, 709 (1984); Angew. Chem. Int. Ed. Eng1. 23, 740 (1984).

51. M.Yoshifuji, T.Hashida, N.Inamoto, K.Hirotsu, T.Horiuchi, T.Higuchi, K.Ito and S.Nagase, Angew. Chem. in press.

52. K.A.Schugart and R.F.Fenske, J. Am. Chem. Soc. 107, 3384 (1985).

53. H.Vahrenkamp and D.Wolters, Angew. Chem, 95,152 (1983); Angew. Chem. Int. Ed. Eng1. 22, 154 (1983); M.M.01mstead and P.P.Power, J. Am. Chem. Soc. 106, 1495 (1984).

54. a) M.Hoefer, K.-F. Tebbe, H.Veit and N.E.Weiler, J. Am. Chem. Soc. 105, 6338 (1983); b) H.Behrens and W.Haag, Chem. Ber. 94, 320 (1961); D.J.Darensbourg and D.J.Zalewski, Organometallics 3,1598 (1984).

55. J.Borm, G.Huttner, O.Orama and L.Zsolnai, J. Organomet. Chem. 282, 53 (1985).

56. A.S.Foust, C.F.Campana, D.Sinclair and L.F.Dah1, J. Am. Chem. Soc. 91, 5633 (1969); A.S.Foust, C.F.Campana, D.Sinclair and L.F.Dah1, Inorg. Chem. 18, 3047 (1979); C.F.Campana, A.Vizi-Orosz, G.Pàlyi, L.Markò and L.F.Dah1, Inorg. Chem. 18, 3054 (1979); A.Vizi-Orosz, G.Pàlyi and L.Marko, J. Organomet. Chem. $\frac{60}{1}, \mathrm{C} 25$ (1973).

57. P.J.Sullivan and A.L.Rheingold, Organometallics 1,1547 (1982); I.Bernal, H.Brunner, W.Meier, H.Pfisterer, J.Wachter and M.L.Ziegler, Angew. Chem. 96, 428 (1984); Angew. Chem. Int. Ed. Eng1. 23,438 (1984).

58. H.Lang, L.Zsolnai and G.Huttner, Angew. Chem. 95, 1017 (1983); Angew. Chem. Int. Ed. Eng1. 22, 976 (1983); Angew. Chem. Supp1. 1983, 1463.

59. 59. 0.J.Scherer, H.Sitzmann and G.Wolmershäuser, Angew. Chem. 96, 979 (1984); Angew. Chem. Int. Ed. Eng1. 23, 968 (1984).

60. B.Sigwarth, L.Zsolnai, H.Berke and G.Huttner, J. Organomet. Chem. 226, C5 (1982).

61. G.Huttner, U.Weber and L.Zsolnai, $Z$. Naturforsch. 37b, 707 (1982).

62. $\mathrm{Bi}_{2}\left(\mathrm{~W}(\mathrm{CO})_{5}\right)_{3}$ has recently also been obtained from $\mathrm{RBiCl}_{2}$ and $\mathrm{Na}_{2} \mathrm{~W}_{2}(\mathrm{CO})_{10}$ : A.M.Arif, A. H. Cowley, N.C.Norman and M.Pakulski, J. Am. Chem. Soc. 107,1062 (1985).

63. O.Scheidsteger, G.Huttner, K.Dehnike and J.Pebler, Angew. Chem. 97, 434 (1985); Angew. Chem. Int. Ed. Eng1 $-24,428$ (1985). 